\title{
FIRE AND EXPLOSION MODELLING FOLLOWING THE ACCIDENTAL FAILURE OF HIGH PRESSURE ETHYLENE TRANSPORTATION PIPELINES
}

\author{
Jianhao Yu, Haroun Mahgerefteh*, Sergey Martynov, \\ Department of Chemical Engineering, University College London, Torrington Place, London WC1E 7JE, \\ UK \\ Tomasz Olewski, Ioannis Economou \& Luc Vechot \\ Texas A\&M University at Qatar \\ Department of Chemical Engineering, Texas A\&M Engineering Building, Education City PO Box 23874, \\ Doha, Qatar
}

\begin{abstract}
This paper presents the development and application of a failure consequence mathematical model for predicting the incident heat flux and explosion over-pressure following the accidental rupture of high pressure ethylene transportation pipelines. The transient discharge rate and the fluid phase at the pipe breach are determined based on the numerical solution of the conservation equations using the Method of Characteristics. The flow model accounts for the important processes taking place during the depressurization process; these include real fluid behaviour, fluid/wall heat transfer and frictional effects. To model the immediate ignition of the escaping high pressure ethylene released, the transient outflow model serving as the source term is linked to the widely established Chamberlain semi-empirical jet fire model to predict the resulting jet flame characteristics including its dimensions and incident heat flux as function of time and distance from the breach location. To deal with a delayed ignition, the source term flow model is linked to the TNO Multi-Energy Vapour Cloud Explosion model to predict the resulting explosion over-pressure and hence the subsequent harm to people and surrounding structures. Simulation results using the model are presented and discussed for the full rupture of a typical $20 \mathrm{~km}$ long, $250 \mathrm{~mm}$ i.d steel pipeline transporting ethylene at $50 \mathrm{bar}$ and $5{ }^{\circ} \mathrm{C}$.
\end{abstract}

KEY WORDS: Fire and explosion, High pressure ethylene transportation, Multiphase flow modelling

\section{INTRODUCTION}

Ethylene is considered as the most important organic chemical by tonnage that is manufactured. It is used as the feed stock for the manufacture of a wide range of chemicals, including polymers such as polyethylene, polystyrene and polyvinyl chloride. The most economic mode for transportation of ethylene is in its supercritical state, using high pressure pipelines. Given that such pipelines can often be hundreds of kilometres long, coupled with the fact that ethylene is highly flammable and explosive, the safe operation of such pipelines is of paramount importance. Pipeline failure can occur due to corrosion, third party damage such as impact with mechanical diggers or ground subsidence ${ }^{1}$. Indeed the recent spate of pipeline rupture incidents, some resulting in numerous fatalities and environmental damage has refocused attention on the safety of such pipelines ${ }^{2}$. In places where pipelines enter urban areas or are sited near to communication routes, the potential for third party damage to pipeline (e.g. when excavation works are not properly controlled) rises significantly. This was graphically demonstrated on 8 June 2010 in Darrouzett, Texas, where the 14" natural gas pipeline damaged during excavation work killed 2 workers and injured 3 others 3 . The following day, a 36" Natural Gas pipeline was damaged during construction in Cleburne, Texas, killing 1 person and injuring $7^{4}$. 
To reduce the risks to a tolerable level through the use of appropriate mitigation measures, and to determine minimum safe distances to populated areas, it is fundamentally important to accurately predict the consequences of pipeline failure.

This paper presents the development and application of a failure consequence mathematical model for predicting the incident heat flux and explosion over-pressure following the rupture of high pressure ethylene transportation pipelines.

\section{METHODOLOGY}

\subsection{Pipeline Decompression Model}

Full details of the pipeline decompression model may be found elsewhere ${ }^{5,6}$ hence only a brief account of its main features is given here. The transient one-dimensional outflow following pipeline rupture for homogeneous equilibrium where the constituent liquid and vapour phases are assumed to be at thermal and mechanical equilibrium (i.e. no phase slip) is presented by the following mass, momentum and energy conservation equations respectively ${ }^{6}$ :

$$
\begin{gathered}
\frac{\partial \rho}{\partial t}+\frac{\partial \rho u}{\partial x}=0 \\
\frac{\partial \rho u}{\partial t}+\frac{\partial\left(\rho u^{2}+p\right)}{\partial x}=-\frac{f_{w} \rho u^{2}}{D} \\
\frac{\partial \rho E}{\partial t}+\frac{\partial(\rho u E+u p)}{\partial x}=-\frac{f_{w} \rho u^{3}}{D}
\end{gathered}
$$

where $\rho, u, E$ and $p$ are respectively the fluid density, velocity, total specific energy and pressure. $x$ and $t$ are respectively the spatial coordinate and time, $D$ is the pipeline internal diameter and $f_{w}$ is the Fanning friction factor, which in the present study is calculated using Chen's correlation ${ }^{7}$. The pertinent thermal equilibrium and fluid phase properties for ethylene are obtained using the Peng-Robinson Equation of State $(\mathrm{PR} \mathrm{EoS})^{8}$, with critical temperature, pressure and acentric factor set at $282.35 \mathrm{~K}, 5.0418 \mathrm{MPa}$ and $0.087^{9}$ respectively.

Following the application of the relevant boundary conditions at the feed point and the rupture plane, the conservation equation 1 to 3 along with the PR EoS and Chen friction factor correlation serving as closure equations are solved numerically using the Method of Characteristics ${ }^{6}$.

\subsection{Jet Fire Modelling}

In order to predict the flame shape and the subsequent incident thermal radiation following the rupture of the high pressure pipeline, the Chamberlain model ${ }^{10,11}$ for hydrocarbon fires is employed. The model represents the flame as a frustum of a cone, radiating as a solid body with a uniform surface emissive power, accounting for flame lift off. In order to determine the geometry of the flame and surface emissive power as functions of the ambient and discharge flow conditions, semi-empirical correlations are used.

\subsection{Explosion Modelling}

The delayed ignition of the release gas will lead to an explosion, creating a blast wave propagating away from the release point. The resulting explosion overpressure associated with the blast wave may pose a significant safety hazard to people and surrounding structures and should therefore be quantified as a part of the safety assessment. For this purpose, the widely established and validated TNO Multi-Energy Vapour Cloud Explosion Model ${ }^{11}$ is employed in the present study. Linked to the transient pipeline decompression model (section 2.1) as the source term, the model predicts the blast overpressure at various distances away from the release point at different time intervals for both un-obstructed and partially obstructed surroundings 


\section{RESULTS AND DISCUSSION}

The pipeline failure simulations are performed for a $20 \mathrm{~km}$ long, $250 \mathrm{~mm}$ i.d thermally insulated (heat transfer coefficient $\left.=6 \mathrm{~kW} / \mathrm{m}^{2} \mathrm{~K}\right), 12 \mathrm{~mm}$ wall thickness steel pipeline, representative of a typical ethylene onshore pipeline $^{12}$. The pipe wall roughness and ambient pressure and temperature are assumed to be 0.05 $\mathrm{mm}, 1$ bara and $20^{\circ} \mathrm{C}$ respectively. The pipeline operating pressure and temperature prior to rupture are assumed to be 90 bar and $5^{\circ} \mathrm{C}$ respectively. The nominal transportation velocity of the ethylene stream prior to pipeline failure is taken as $1 \mathrm{~m} / \mathrm{s}$.

In the following examples of the main results obtained using the above failure model are presented and discussed. Figure 1 shows the incident heat flux radiation contours at the ground level for receiver distance of $+/-200 \mathrm{~m}$ from the vertical jet flame base at $0.5,2,10$ and $50 \mathrm{~s}$ after pipeline rupture in still air with relative humidity of 50\%. As expected the incident heat flux decreases with the distance from the centre of the jet whilst decaying with time, reaching its maximum of ca. $3 \mathrm{~kW} / \mathrm{m}^{2}$ corresponding to $2^{\text {nd }}$ degree burn for an exposed individual in $90 \mathrm{~s}{ }^{13}$.
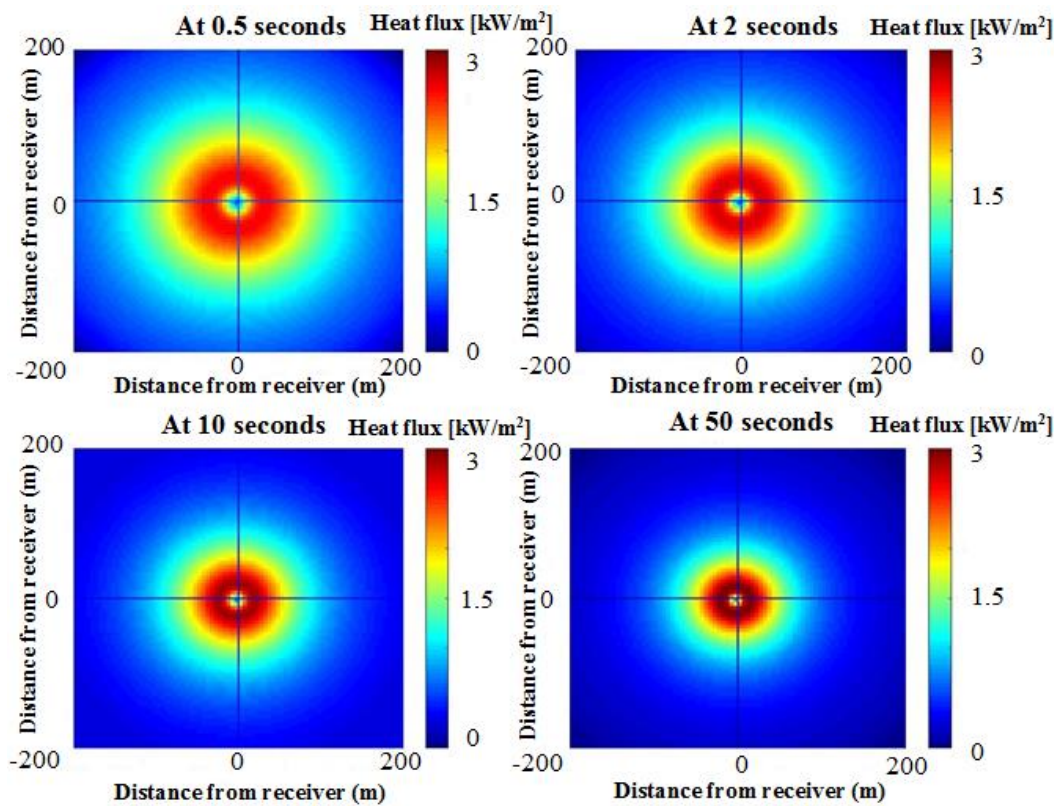

Fig 1. Incident heat flux contours at the ground level around vertical flame formed from the rupture plane at $(0 ; 0)$, predicted at $0.5,2,10$ and $50 \mathrm{~s}$ following the rupture.

Figure 2 shows the predicted variation of peak overpressure as a function of distance from the explosion source located at the rupture plane. The results are plotted for unconfined (in the open) and partillay confined explosions (e.g explosion in a plant) with various volumes of confinement. The two hazardous overpressure thresholds of 70 mbar (risk of fatality in confined spaces $^{13}$ ) and 300 mbar (eardrum rupture for people in the open ${ }^{13}$ ) are also indicated in the same figure for reference. As it may be

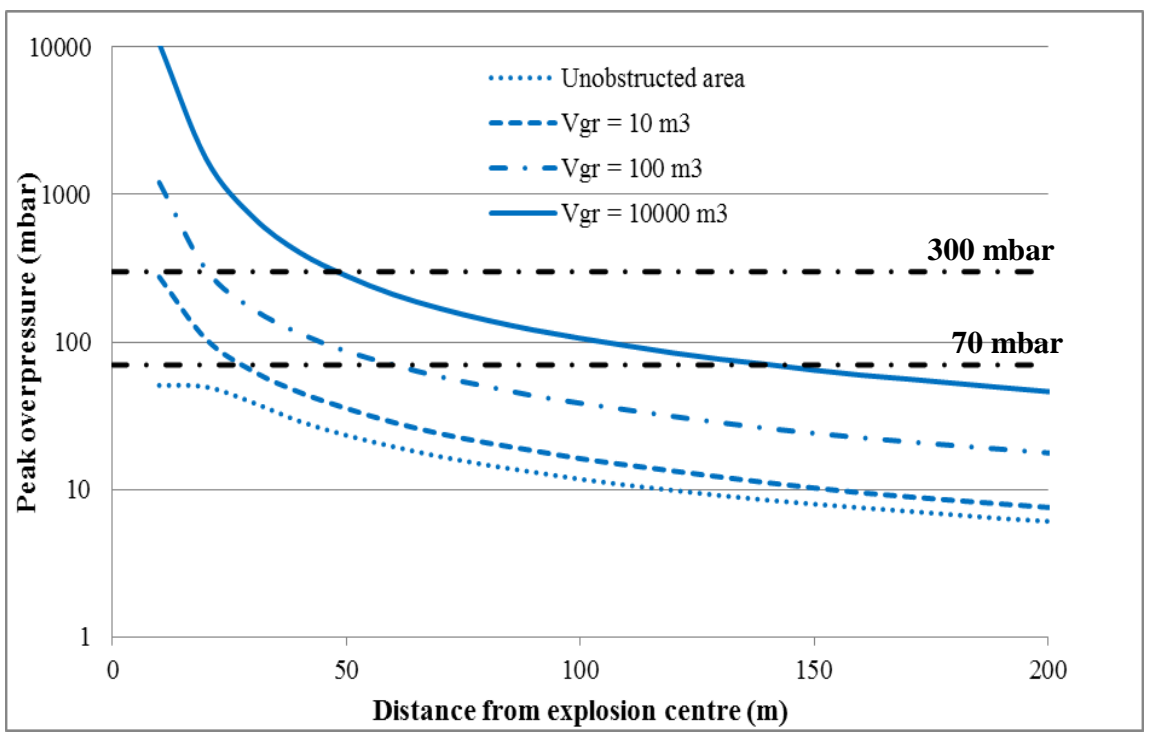

Fig 2. Explosion overpressure as a function of distance from the explosion source 
observed in all cases the peak overpressure, as expected, drops with distance from the receiver, but increases as the degree of confinement increases. Also, for the conditions tested, an explosion in the open space falls below the 70 mbar peak overpressure threshold required to cause harm to people. This is in contrast to an explosion in partially confined spaces where fatalities will be expected at distances less than $50 \mathrm{~m}$ from the point of detonation.

\section{CONCLUSIONS}

The development of a transient computational fluid flow model linked to established empirically based jet fire and explosion correlations for determining the minimum safe distances following the accidental failure of high pressure pipelines is presented. The model is tested by simulating the full rupture of a high pressure ethylene pipeline. The simulation results are presented in the form of 2D plots of thermal radiation contours and explosion over-pressure/distance profiles, for the first time providing valuable data for process design and safety engineers determine minimum safe distances at different time frames following pipeline failure.

\section{ACKNOWLEDGMENT}

This research was supported by Qatar National Research Fund (a member of The Qatar Foundation) NPRP award 8-1339-2-569. The statements made herein are solely the responsibility of the authors.

\section{REFERENCES}

[1] HSE, Update of Pipeline Failure Rates for Land Use Planning Assessments. Retrieved Sept 25, 2018, from http://www.hse.gov.uk/research/rrpdf/rr1035.pdf, (2015).

[2] Papadakis, Georgios A. "Major hazard pipelines: a comparative study of onshore transmission accidents," Journal of Loss Prevention in the Process Industries, 12(1), pp. 91-107, (1999).

[3] CNN Wire Staff, 2 dead in Texas Panhandle pipeline explosion. Retrieved Sept 21, 2018, from http://www.cnn.com/2010/US/06/08/texas.pipeline.explosion, (2010).

[4] National Transportation Safety Board, Enterprise Products Natural Gas Pipeline Excavation Damage, Rupture, and Fire Cleburne, Texas - June 7, 2010. Retrieved Sept 21, 2018, from https://www.ntsb.gov/investigations/AccidentReports/Pages/PAB1302.aspx, (2010).

[5] Mahgerefteh, H., Oke, A. and Atti, O., "Modelling Outflow Following Rupture in Pipeline Networks," Chemical Engineering Science, 61(6), pp. 1811-1818, (2006).

[6] Mahgerefteh, H., Saha, P. \& Economou, I.G., "A Study of the Dynamic Response of Emergency Shutdown Valves Following Full Bore Rupture of Gas Pipelines," Trans IChemE Part B, 75, pp.201-209, (1997).

[7] Chen, N.H., “An Explicit Equation for Friction Factor in Pipe," Industrial \& Engineering Chemistry Fundamentals, 18(3), pp.296-297, (1979).

[8] Peng, D.-Y. \& Robinson, D.B., “A New Two-Constant Equation of State," Industrial \& Engineering Chemistry Fundamentals, 15(1), pp.59-64.(1976).

[9] Reid, R.C., Prausnitz, J.M. \& Poling, B.E., The Properties of Gases and Liquids, 5th Ed., NY, USA: McGraw-Hill, (2001).

[10] Chamberlain G. A., "Developments in Design Methods for Predicting Thermal Radiation from Flares," Chem. Eng. Res. Des., 65(4), pp. $299-309,(1987)$.

[11] TNO, Methods for the Calculation of Physical Effects, 3rd Ed., The Hague: TNO, (2005).

[12] Saville, G., Richardson, S.M. \& Barker, P., "Leakage in Ethylene Pipelines," Process Safety and Environmental Protection, 82(1), pp.61-68, (2004).

[13] DOT, Handbook of Chemical Hazard Analysis Procedures. Federal Emergency Management Agency, U.S. Department of Transportation, and U.S. Environmental Protection Agency. Washington, D.C.: Federal Emergency Management Agency Publications Office, 1988. 